\title{
TEMPERATURE VARIATIONS IN MIXED-SAND-GRAVEL SEDIMENTS AT A STEEP, MEGA-TIDAL BEACH
}

\author{
Arash Tavakoli, Virginia Polytechnic Institute and State University, arasht@vt.edu \\ Nina Stark, Virginia Polytechnic Institute and State University, ninas@vt.edu
}

Alex E. Hay, Dalhousie University, alex.hay@dal.ca

\section{MOTIVATION}

The increasing urbanization of coastal regions makes beach erosion and coastline protection an important field of research (Elko et al., 2014). Excess pore pressures and pore pressure gradients in the soil matrix can impact sediment mobilization and erosion in terms of liquefaction (Sumer, 2014). Despite previous studies, there are still unsolved questions regarding coastal liquefaction due to wave action. Particularly, the role of groundwater dynamics, the impact of wave breaking, sediment reorganization, and potential air content represent unsolved problems. Furthermore, open questions still exist regarding the interaction and roles of excess pore pressure built-up, vertical pressure gradients and horizontal pressure gradients (Foster et al., 2006; Yeh and Mason, 2014; Sumer, 2014; Stark, 2017). We hypothesize that temperature variations may reveal complementary information with regard to pore water fluid behavior, such as pore space saturation, groundwater flows, exfiltration and infiltration processes, and impact of wave forcing. The study presented here shows some preliminary data sets of combined pore pressure and temperature recordings.

\section{METHODOLOGY}

Pore pressure and temperature variations were measured with regard to local hydrodynamic forcing and possible sediment transport. A vertical array of pressure and temperature sensors was deployed in the central intertidal zone of a steep ( $7^{\circ}$ slope), mixed-sand-gravel, mega-tidal beach in Advocate, Nova Scotia, Canada. Three sensors were buried at sediment depths of $5 \mathrm{~cm}, 20$ $\mathrm{cm}$, and $60 \mathrm{~cm}$. The sensors were logging continuously at a sampling frequency of $6 \mathrm{~Hz}$ over a duration of 43 tidal cycles, between 21st of October and 11th of November 2013 (yeardays 294 to 315). The first recorded tidal cycles were removed from analysis to minimize effects of sediment disturbance from the initial sensor deployment.

\section{RESULTS}

For this preliminary study, pressure and temperature variations were analyzed for three chosen tidal cycles during storm (tidal cycle 16; significant wave height $\sim 100$ $\mathrm{cm}$ ) and pre-storm conditions (tidal cycles 5 and 7; significant wave heights 20 and $10 \mathrm{~cm}$ ), respectively. Figures 1 and 2 show the pressure and temperature recordings of tidal cycles 5 (yearday 296) and 16 (yearday $301)$, respectively. The tidal water level elevations including high tide and a following drainage phase are clearly visible in both data sets. The significant increase in wave energy and height is reflected in stronger pressure fluctuations during tidal cycle 16 (Figure 2). During tidal cycle 5, temperature profiles throughout the tidal cycle varied noticeably between the measured sediment depths. During tidal cycle 16 and more energetic wave conditions, temperature profiles throughout the tidal cycle exhibited a similar trend at the measured sediment depths. The detailed temperature profiles are indicated as

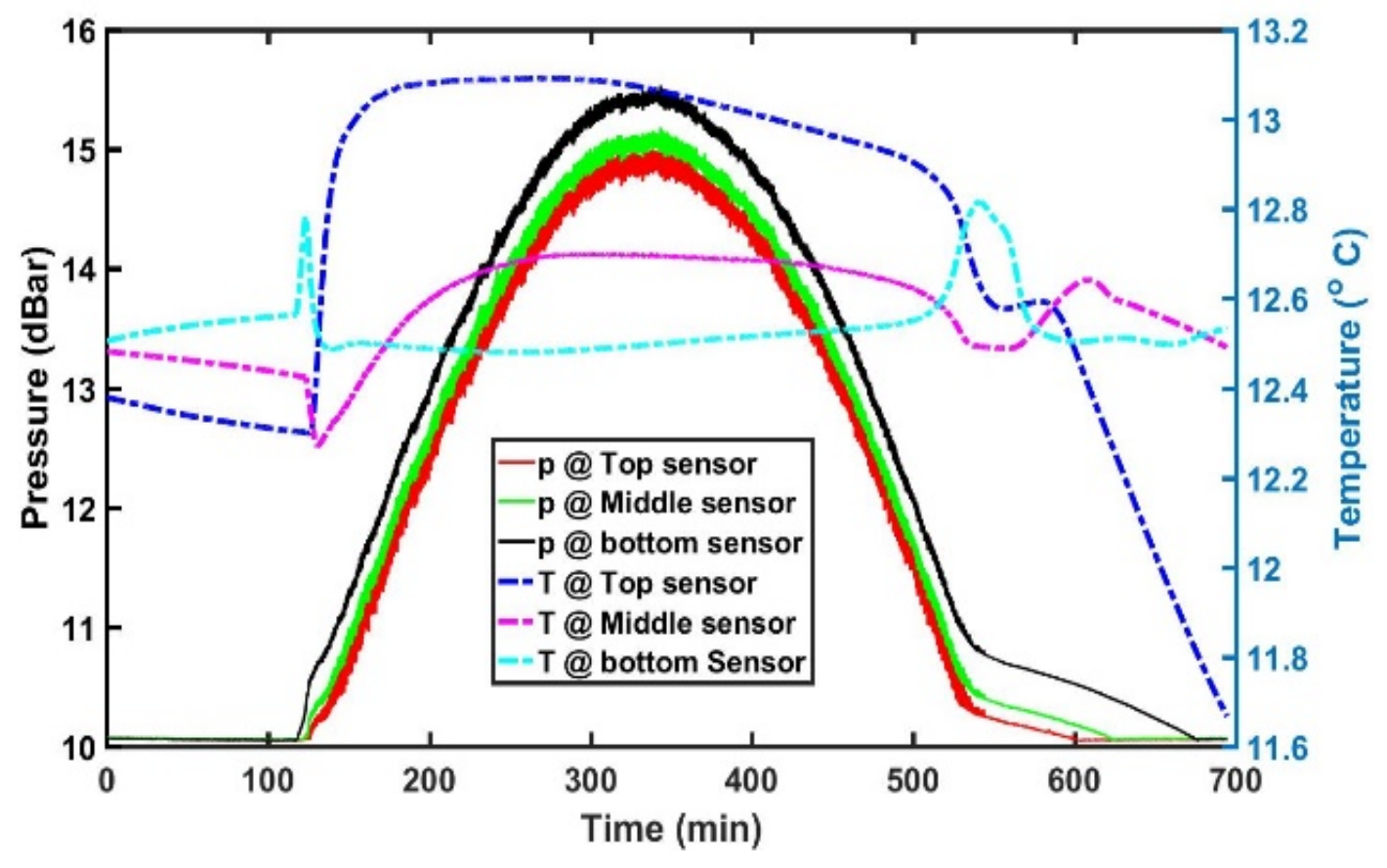

Figure 1 - Pressure (solid lines) and temperature (dashed lines) variations over tidal cycle 5 (yearday 296, pre-storm conditions) measured at $5 \mathrm{~cm}$ (top), $20 \mathrm{~cm}$ (middle), and $60 \mathrm{~cm}$ (bottom) sediment depth. 


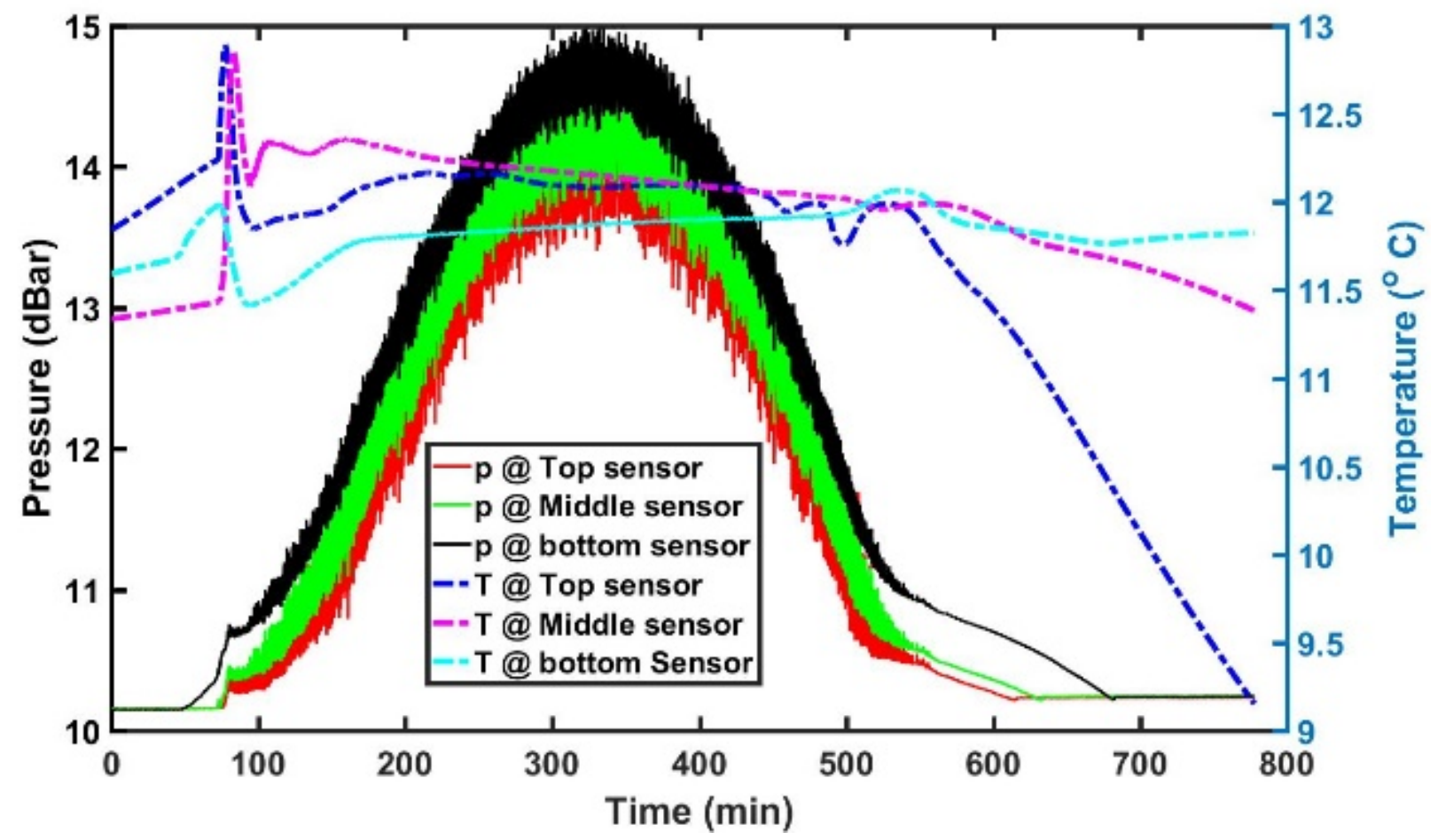

Figure 2 - Pressure (solid lines) and temperature (dashed lines) variations over tidal cycle 16 (yearday 301, storm conditions).

dashed lines in figures 1 and 2. Generally, phases of infiltration, submergence, drainage, and low water were related to variations in temperature.

\section{DISCUSSION}

Temperature variations appeared to be associated with four processes: infiltration of water into the beachface, wave forcing, groundwater flow, and air ventilation. Temperature differences between air and water helped with the identification of these processes. For instance, air ventilation was indicated during the drainage phase and at the point of decoupling of sediment drainage and the tidal ebb tide by a noticeable decrease in temperature, resulting from the temperature difference between air and water. During full submergence of the measurement locations, surface waters governed the temperature at sediment depths of at least $20 \mathrm{~cm}$ during calm to moderate wave forcing, while surface waters still impacted the temperature signature at a sediment depth of $60 \mathrm{~cm}$ during energetic wave forcing. Passing of warmer groundwater from upslope was observed over a second period of the drainage phase. This may serve as a tracer for the groundwater flow during drainage. Finally, friction from sediment transport may be reflected in shortterm heat generation, and sediment drying seemed to be directly correlated to sediment cooling.

\section{CONLUDING REMARKS}

Temperature measurements suggested to provide complementary information about sediment air ventilation, sediment motion, and groundwater flow paths if temperatures between air and water differ noticeably. This may contribute to answer questions raised by Stark and Hay (2014) and Guest and Hay (2017) investigating wave attenuation and potential sediment liquefaction due to ocean wave forcing at beaches.

This data set only represents a small insight into a larger data set during the experiment at Advocate Beach. Nevertheless, more data is needed to understand the interaction between temperature and pore pressure recordings, and therefore, sediment, surface water and ground water interaction in more detail. However, this approach appeared as a feasible opportunity to collect valuable complementary data.

\section{REFERENCES}

Elko, Feddersen, Foster, Hapke, McNinch, Mulligan, Raubenheimer (2014). The future of nearshore processes research. 2014 AGU Fall Meeting, OS22A-08.

Foster, Bowen, Holman, Natoo (2006). Field evidence of pressure gradient induced incipient motion. Journal of Geophysical Research: Oceans, 111(C5).

Guest, Hay (2017). Vertical structure of pore pressure under surface gravity waves on a steep, megatidal, mixed sand-gravel-cobble beach. Journal of Geophysical Research: Oceans, 122(1), 153-170.

Stark, Hay (2014). Pore water infiltration and drainage on a megatidal beach in relation to tide-and wave-forcing. Coastal Engineering Proceedings, 1(34), 25.

Stark (2017). Pore pressure response to irregular waves at a sandy beach. Geotechnical Frontiers 2017, 409-417. Sumer, (2014). Liquefaction Around Marine Structures:(With CD-ROM). World Scientific.

Yeh, Mason (2014). Sediment response to tsunami loading: mechanisms and estimates. Geotechnique, 64(2), 131-143. 